\title{
Selected Topics on Complex Systems Informatics: Editorial Introduction to Issue 23 of CSIMQ
}

\author{
Kurt Sandkuhl* \\ University of Rostock, Chair Business Information Systems, \\ Albert-Einstein-Str. 22, 18059 Rostock, Germany \\ Kurt.Sandkuhl@uni-rostock.de
}

Complex systems and their analysis, construction, management or application are the motivation of all articles in this issue of CSIMQ. Different perspectives exist on what actually causes "complexity" in systems. In systems theory, a widely spread view is that complex systems have many components with emergent behavior [1], [2], i.e. the large number and the dynamics of components are decisive. In business informatics, the complexity of information systems is attributed to their socio-technical nature [3], which acknowledges the interaction between the human actors and the information technology in an enterprise, i.e. the human is part of the system and affects the complexity.

Modeling is an important contribution to dealing with complexity in design and development projects. Complex systems are difficult to model due to the dependencies, relationships and different kinds of interactions between their components. Understanding the context of complex systems or their components is supported by modeling and is a key aspect of preparing organizational solutions. Models do not remove the complexity of the real world but help to understand it and to design and develop solutions. All articles in this issue are in some respect concerned with models or modeling.

The articles in this issue also reflect recent trends in industry and society, such as digital transformation [4] and applications of artificial intelligence [5], and show that these trends will not necessarily reduce complexity in systems but rather require the combination of proven approaches, such as modeling, and new methods for managing this complexity.

The following articles were accepted by the reviewers:

- Grassroots business intelligence as an enabler of change management is the topic of Nakayama, Isik, Sutcliffe and Olbrich. The authors focus on a case study of a large manufacturing company and their observations suggest that companies may consider business intelligence as an enabler of change management rather than simply technical tools that extend the traditional IT-systems environment.

- The work of Granosik and Lewańska addresses a topic in the scope of artificial intelligence applications. Using financial and spatial data, the authors present an application of

\footnotetext{
* Corresponding author
}

(C) 2020 Kurt Sandkuhl. This is an open access article licensed under the Creative Commons Attribution License (http://creativecommons.org/licenses/by/4.0).

Reference: K. Sandkuhl "Selected Topics on Complex Systems Informatics: Editorial Introduction to Issue 23 of CSIMQ," Complex Systems Informatics and Modeling Quarterly, CSIMQ, no. 23, pp. I-II, 2020. Available: https://doi.org/10.7250/csimq.2020-23.00

Additional information. Author's ORCID iD: K. Sandkuhl - https://orcid.org/0000-0002-7431-8412. PII S225599222000131X. Received: 24 July 2020. Available online: 31 July 2020. 
unsupervised machine learning to detect criminal activity in the UK in which young people are being forced to participate in drug dealing. The core activity is automatic detection of county lines criminal scheme.

- Srinivas, Gill and Roach discuss the role of enterprise architectures and, in particular, business architectures in a changing competitive business landscape. The authors propose an analytics-enabled approach to business architecture that is demonstrated through its use in a health insurance.

- Ozmermer proposes a new neural network algorithm, called sinusoidal neural network (SNN), which seems to reach high accuracy rates faster than the standard neural networks. The experiments presented in the article show promising results, but also lead to the conclusion that further research is necessary to test if in real-life cases SNNs are capable of learning faster than existing algorithms.

- Staegemann, Volk, Daase and Turowski address in their work challenges of dynamic business environments and big data analytics (BDA). They provide an overall overview about influences of dynamic business environments, particularly focusing on BDA applications, but also analyze general shortcomings during BDA implementation based on expert interviews.

The CSIMQ editorial team would like to thank the reviewers of this issue for providing valuable comments and improvement proposals for the submitted articles.

\section{References}

[1] Y. Bar-Yam, Dynamics of complex systems. Studies in Nonlinearity. Perseus Books, 1997. Available: https://doi.org/10.1063/1.4822633

[2] G. J. Klir, G J (1985) “Complexity: some general observations,” Systems Research and Behavioral Science, vol. 2, no. 2, pp. 131-140, 1985. Wiley. Available: https://doi.org/10.1002/sres.3850020205

[3] G. Piccoli and F. Pigni, Information Systems for Managers, $4^{\text {th }}$ edition. Prospect Press, 2018.

[4] C. Matt, T. Hess, and A. Benlian, "Digital transformation strategies," Business \& Information Systems Engineering, Springer, vol. 57, no. 5, pp. 339-343, 2015. Available: https://doi.org/10.1007/s12599-015-0401-5

[5] S. Russell and P. Norvig, Artificial intelligence: a modern approach. Pearson, 2016. 